\title{
Produtividade e rendimento do cafeeiro submetido a lâminas de irrigação
}

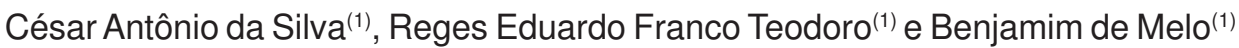

(1)Universidade Federal de Uberlândia, Instituto de Ciências Agrárias, Avenida Amazonas, s/no, Bloco 2E, Sala 13, Campus Umuarama, CEP 38400-902 Uberlândia, MG. E-mail: cesar.ufu@gmail.com, reges@umuarama.ufu.br, benjamim@umuarama.ufu.br

\begin{abstract}
Resumo - O objetivo deste trabalho foi avaliar a produtividade e o rendimento das quatro primeiras safras de cafeeiro (Coffea arabica L.), cultivado sob lâminas de irrigação. O experimento foi conduzido na Fazenda Experimental do Glória, Uberlândia, MG. O delineamento experimental foi o de blocos ao acaso, com quatro repetições e oito tratamentos constituídos das lâminas de irrigação equivalentes a 0 (sem irrigação), 30, 60, 90, 120, 150, 180 e 210\% da evaporação em tanque Classe A (ECA). O plantio foi realizado em janeiro de 2001, no espaçamento de 3,5x0,7 m. As parcelas foram constituídas por três linhas com oito plantas cada. Foi utilizado o sistema de irrigação por gotejamento, com emissores autocompensantes de vazão $3,5 \mathrm{~L} \mathrm{~h}^{-1}$. A produtividade máxima foi de 115 sacas ha $^{-1}$, obtida com a lâmina de $164,1 \%$ da ECA. A reposição de $143 \%$ da ECA propiciou rendimento ótimo de 291,8 L de "café da roça" por saca beneficiada. O efeito das lâminas de irrigação sobre a produtividade e o rendimento depende do ano. A irrigação não ameniza a bienalidade da produção do cafeeiro, em relação às plantas cultivadas em sequeiro.
\end{abstract}

Termos para indexação: Coffea arabica, bienalidade de produção, deficiência hídrica, gotejamento.

\section{Productivity and yield of coffee plant under irrigation levels}

\begin{abstract}
The objective of this work was to evaluate the productivity and yield of the first four crops of coffee plants (Coffea arabica L.) cultivated under irrigation levels. The experiment was carried out at Fazenda Experimental do Glória, in the County of Uberlândia, MG, Brazil. It was used the randomized blocks design, with eight treatments and four repetitions. The irrigation levels were 0 (without irrigation), 30, 60, 90, 120, 150, 180 and $210 \%$ of the evaporation measured in Class A tank (ECA). Planting took place in January 2001, at 3.5x0.7 m spacing. Plots consisted of three rows with eight plants each. A drip irrigation system was used, with self compensating drippers at $3.5 \mathrm{~L} \mathrm{~h}^{-1}$ flow. Maximum productivity was 115 sacks ha-1, obtained under $164.1 \%$ ECA. Replenishment of $143 \%$ ECA led to optimum yield $291.8 \mathrm{~L}$ of "farm coffee" per processed sack. The effect of irrigation levels on productivity and yield depends on the year. Irrigation does not mitigate the production biannuality of coffee plants, regarding plants cultivated without irrigation.
\end{abstract}

Index terms: Coffea arabica, biannuality of production, water deficit, drip irrigation.

\section{Introdução}

A expansão da cafeicultura brasileira em áreas marginais, como a Região do Triângulo Mineiro, onde as chuvas são insuficientes ou mal distribuídas no decorrer do ano, tornou a irrigação uma prática necessária para a obtenção de boa produtividade (Fernandes et al., 2000; Karasawa et al., 2002).

A irrigação visa atender à demanda de água das plantas nos períodos críticos, e é necessário aplicá-la em quantidade correta. Se insuficiente, prejudica o desenvolvimento do sistema radicular e, se em excesso, provoca desperdícios de água, energia e nutrientes
(Camargo, 1985). A deficiência hídrica na fase de chumbinho (outubro a dezembro) atrasa o crescimento dos frutos e reduz a produtividade do cafeeiro. O tamanho final dos grãos é fortemente associado à precipitação ocorrida no período de 10 a 17 semanas após o florescimento, período este considerado de expansão rápida do fruto (Camargo, 1987).

A irrigação tem propiciado aumentos na produtividade, tanto em regiões onde a deficiência hídrica coincide com o estádio de frutificação, como em regiões aptas ao cultivo, como o Sul de Minas Gerais (Matiello, 1991; Faria \& Siqueira, 2005; Gomes et al., 2007). No Brasil, $22 \%$ da produção nacional de café é proveniente de 
áreas irrigadas, o que corresponde a apenas 220 mil ha, $10 \%$ da área total plantada com café (Saturnino, 2007).

Em Planaltina de Goiás, a irrigação ao longo de todo o ano propiciou acréscimos na produtividade do cafeeiro 'Mundo Novo', de mais de 100\%, em relação às áreas não irrigadas, e de até $32 \%$, em relação às áreas irrigadas apenas no período seco (Fernandes et al., 2000).

Observa-se, no Brasil, a ocorrência alternada de altas e baixas produções. Essa alternância é comumente atribuída ao esgotamento das reservas das plantas, em anos de safra alta, o que faz com que a produção, no ano seguinte, seja baixa (Moreira, 2003; Santos, 2005). Faria \& Siqueira (2005) verificaram, no entanto, que a irrigação não reduz o efeito bienal da produtividade, e tem causado desuniformidade de maturação, em razão do aumento no número de floradas.

São poucas as informações relativas ao suprimento racional de água ao cafeeiro, e não estão definidos, ainda, os critérios de manejo da irrigação, no que se refere a quando irrigar e quanto irrigar.

A maioria dos trabalhos sobre irrigação no cafeeiro avalia apenas a produtividade, e não o rendimento, que é um importante parâmetro no cálculo de custos e de receitas da lavoura, e se limitam a comparações entre lavouras irrigadas e não irrigadas, sem determinação de lâminas de água que melhor satisfaçam as necessidades hídricas da cultura.

Em Lavras, a lâmina de $100 \%$ da ECA promoveu, na primeira colheita da cultivar Acaiá MG-1474, um acréscimo na produtividade de $53,9 \%$, em relação à testemunha (Alves, 1999). Essa lâmina foi a de melhor viabilidade econômica, nas três primeiras safras dessa cultivar, e propiciou uma produtividade média de 68 sacas ha $^{-1}$ (Silva et al., 2003)

Também em Lavras, a produtividade do cafeeiro 'Topázio MG-1190', aos 28 meses de idade, foi intensamente influenciada pela irrigação. $\mathrm{O}$ tratamento irrigado o ano todo, com reposição de $120 \%$ da ECA, produziu quase 15 vezes mais que a testemunha (Karasawa, 2001). Esse autor obteve rendimento de $408 \mathrm{~L}$ por saca, ao aplicar $120 \%$ da ECA, enquanto o pior resultado (470,5 L por saca) ocorreu nas plantas não irrigadas.

No cafeeiro 'Acaiá MG-1474', foram observados rendimentos de $428,9 \mathrm{~L}$ por saca, com a lâmina de $100 \%$ da ECA, a 562,2 L por saca na ausência de irrigação
(Vilella, 2001). Além disso, o uso de diferentes níveis de irrigação $(0,60,80,100,120$ e $140 \%$ da ECA) por pivô central, no cafeeiro 'Rubi', em Lavras, não promoveu diferença significativa no rendimento das duas primeiras safras dessa cultivar (Vilela et al., 2002).

Trabalhos desenvolvidos por Gervásio (1998), Vilella (2001) e Rotondano (2004) são precursores de metodologia para manejo da irrigação do cafeeiro, porém, enfocam apenas até a segunda safra do cafeeiro. Para se obterem respostas mais abrangentes, é imprescindível avaliar o efeito da irrigação sobre a produção do cafeeiro, ao longo de vários anos.

O objetivo deste trabalho foi avaliar a produtividade e o rendimento do cafeeiro (Coffea arabica L.), cultivado sob lâminas de irrigação, durante as quatro safras iniciais.

\section{Material e Métodos}

O experimento foi realizado de janeiro de 2001 a julho de 2006, no Setor de Irrigação da Fazenda Experimental do Glória, da Universidade Federal de Uberlândia. A área está a $18^{\circ} 58^{\prime} \mathrm{S}, 48^{\circ} 12^{\prime} \mathrm{W}$ e à altitude média de $890 \mathrm{~m}$.

Segundo a classificação de Köppen, o clima local é do tipo Cwa, com duas estações bem definidas, com inverno seco e verão quente e chuvoso (Ometto, 1981).

O solo é classificado como Latossolo Vermelho distrófico, de textura argilosa, e a topografia do terreno é levemente ondulada. As operações de preparo do solo consistiram de aração única com duas gradagens, e o solo foi corrigido, antes do plantio, pela aplicacão de $800 \mathrm{~kg} \mathrm{ha}^{-1}$ de calcário dolomítico, com o objetivo de se elevar a saturação por bases a $60 \%$.

Em seguida, foram abertos sulcos de $40 \mathrm{~cm}$ de profundidade, que receberam corretivo complementar e fonte de fósforo, conforme resultado da análise química de amostras de solo coletadas à profundidade de $0 \mathrm{a} 20 \mathrm{~cm}$.

O plantio foi realizado em 15 de janeiro de 2001, no espaçamento de 3,5 mentre linhas, e 0,7 mentre plantas. Foram utilizadas mudas de cafeeiro da cultivar Rubi MG-1192.

Nas adubações de cobertura, em pós-plantio, foram aplicados $15 \mathrm{~g}$ de $\mathrm{K}_{2} \mathrm{O}$ e $4 \mathrm{~g}$ de $\mathrm{N}$ por planta, na forma convencional, tendo-se utilizado como fontes o cloreto de potássio e o sulfato de amônio. As adubações de formação e as do primeiro e segundo anos após o plantio foram realizadas conforme recomendações da Comissão de Fertilidade de Solos do Estado de Minas Gerais, 5 aproximação (Guimarães et al., 1999). 
As adubações de produção foram calculadas com base na análise química de solo, de amostras coletadas anualmente na projeção da copa das plantas (Guimarães et al., 1999). Foi utilizado o fertilizante $20-5-20$, e as dosagens foram divididas em quatro aplicações convencionais (com trator), distribuídas de outubro a março, na região da "saia" das plantas.

Todos os micronutrientes foram fornecidos via foliar, em quatro pulverizações anuais, com a utilização de $480 \mathrm{~L} \mathrm{ha}^{-1}$ de calda, por aplicação. No preparo de $2.000 \mathrm{~L} \mathrm{de} \mathrm{calda,} \mathrm{foram} \mathrm{misturados} 10 \mathrm{~kg}$ de ácido bórico, $10 \mathrm{~kg}$ de sulfato de zinco, $6 \mathrm{~kg}$ de sulfato manganoso e $10 \mathrm{~kg}$ de sulfato de cobre. Também foram adicionados $10 \mathrm{~kg}$ de uréia, $6 \mathrm{~kg}$ de cloreto de potássio, $10 \mathrm{~kg}$ de cal hidratada e $1 \mathrm{~L}$ de espalhante adesivo.

As plantas invasoras foram manejadas com roçadeira nas entrelinhas, conforme a necessidade, e pulverização dirigida de glifosato próximo à linha de plantio, de acordo com o grau de infestação.

As doenças foram controladas com a utilização de fungicidas (azoxistrobina e tebuconazole), e os insetospraga, com a aplicação dos princípios ativos fenpropatrina, deltametrina + triazofós, cloridrato de cartap e etiona, sempre aos primeiros sinais de ataque.

$\mathrm{O}$ delineamento experimental foi o de blocos ao acaso, com oito tratamentos e quatro repetições. Os tratamentos foram constituídos das lâminas de irrigação correspondentes a 0 (sem irrigação), 30, 60, $90,120,150,180$ e $210 \%$ da evaporação de água em tanque Classe A, com aplicação inicial dos tratamentos em agosto de 2001. A escolha dos tratamentos se baseou em trabalhos já realizados com a cultura do cafeeiro, como os de Gervásio (1998) e Karasawa (2001), que ao aplicar lâminas de 0 a $100 \%$ e de 0 a $120 \%$ da ECA, respectivamente, obtiveram, em Lavras, melhor desenvolvimento vegetativo e resposta linear crescente da produtividade à lâmina de irrigação. Como na Região do Triângulo Mineiro a quantidade anual de chuvas é ligeiramente menor do que em Lavras, optou-se por maiores valores de reposição de água.

Cada parcela foi composta por três fileiras de oito plantas, tendo sido avaliadas as quatro plantas centrais da fileira central; as demais constituíram a bordadura.

Foi implantado o sistema de irrigação por gotejamento, com emissores autocompensantes do tipo RAM, espaçados em $0,75 \mathrm{~m}$, entre si, com vazão de $3,5 \mathrm{~L} \mathrm{~h}^{-1}$ sob pressão de serviço de 50 a $400 \mathrm{kPa}$, especificada pelo fabricante.

O turno de rega foi fixo, e as irrigações eram realizadas sempre às segundas, quartas e sextas-feiras. Para o cálculo da lâmina total necessária (LTN), considerou-se a evaporação no tanque (ECA) e o valor do tratamento (Trat), em decimal, tendo-se descontado o valor em milímetros da precipitação pluvial (P) acumulada entre duas irrigações consecutivas, conforme a equação: $\mathrm{LTN}=($ ECA $x$ Trat $)$ - P. A irrigação não foi realizada quando $\mathrm{P} \geq$ (Trat $\mathrm{x}$ ECA). A uniformidade de irrigação foi avaliada anualmente. Os valores de CUC (coeficiente de uniformidade de Christiansen) mantiveram-se acima de $90 \%$, nos quatro primeiros anos do experimento. Apenas no último ano, o valor de CUC foi um pouco menor, de $88,3 \%$. Nos quatro anos de avaliação da produção (2003, 2004, 2005 e 2006), a colheita foi realizada por meio de derriça manual no pano, iniciada quando o percentual de frutos verdes estava entre 10 e $15 \%$. Houve varrição do café de chão apenas em 2004 e 2005, em razão da maior queda de frutos secos nesses anos.

No dia da colheita, foi mensurado o volume (L) de frutos colhidos em cada parcela, do qual foi retirada uma amostra de $5 \mathrm{~L}$, de cada repetição, que foram acondicionadas em embalagens de malha aberta.

As amostras foram expostas ao sol até atingir a umidade de beneficiamento (entre 11 e 12\%). Durante a noite, foram protegidas do orvalho, e ao longo do dia, revolvidas várias vezes para que a secagem ocorresse de forma homogênea. Em seguida, foram retirados $500 \mathrm{~g}$ de café em coco para o beneficiamento e, posteriormente, foram determinados: o peso do café beneficiado, a umidade, a produtividade (sacas por hectare) e o rendimento (L por saca).

Os dados originais foram submetidos aos testes de normalidade de resíduos, de Shapiro-Wilk, e de homogeneidade das variâncias, de Bartlett. Em seguida, aplicou-se a análise de variância (teste F), a 1 e 5\% de probabilidade (Banzatto \& Kronka, 2006), com uso do SISVAR.

Os dados significativos foram submetidos à análise de regressão polinomial, para estimação da lâmina ótima, para cada colheita. Para complementar as análises individuais, foi realizada a análise conjunta, com o intuito de se verificar a possível interação dos fatores lâmina e ano. 


\section{Resultados e Discussão}

Em média, nos meses de janeiro e dezembro, foram registradas as maiores precipitações pluviais, de 427,7 e $336,3 \mathrm{~mm}$, respectivamente, que coincidiram com a fase de enchimento de grãos. $\mathrm{O}$ volume de chuva nesses dois meses correspondeu a $44 \%$ da precipitação média anual no período avaliado (Figura 1). Os maiores índices médios de evaporação ocorreram nos meses de agosto a outubro (Figura 2), em consequiência principalmente da baixa umidade relativa do ar registrada nesse período.

Nota-se que houve um balanço hídrico negativo, no intervalo de abril a outubro, em que a evaporação média mensal foi maior que a precipitação, o que não satisfez por completo a demanda hídrica das plantas. Segundo Camargo (1987), a deficiência hídrica nos estádios de

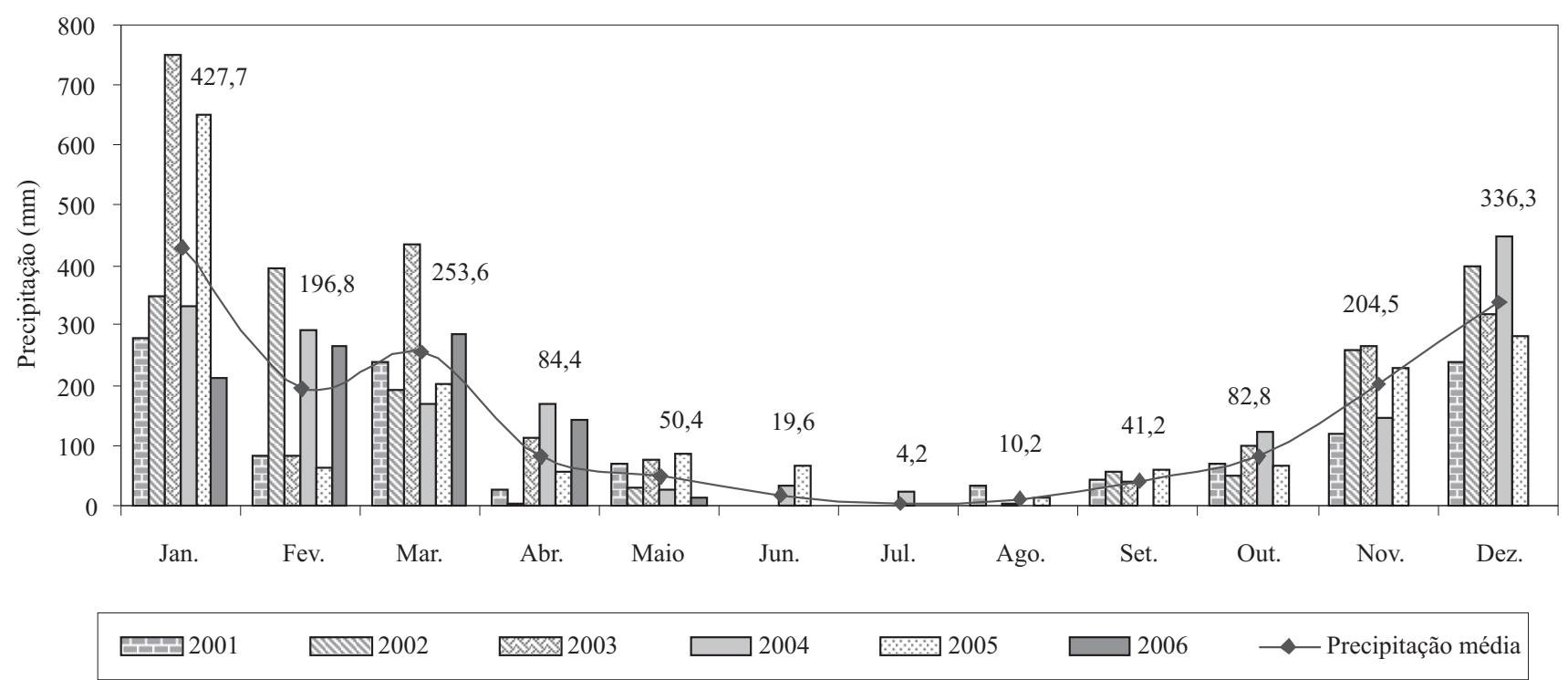

Figura 1. Precipitação pluvial na Fazenda Experimental do Glória, Uberlândia, MG, de janeiro 2001 a maio de 2006 (valores acima das colunas referem-se às médias mensais).

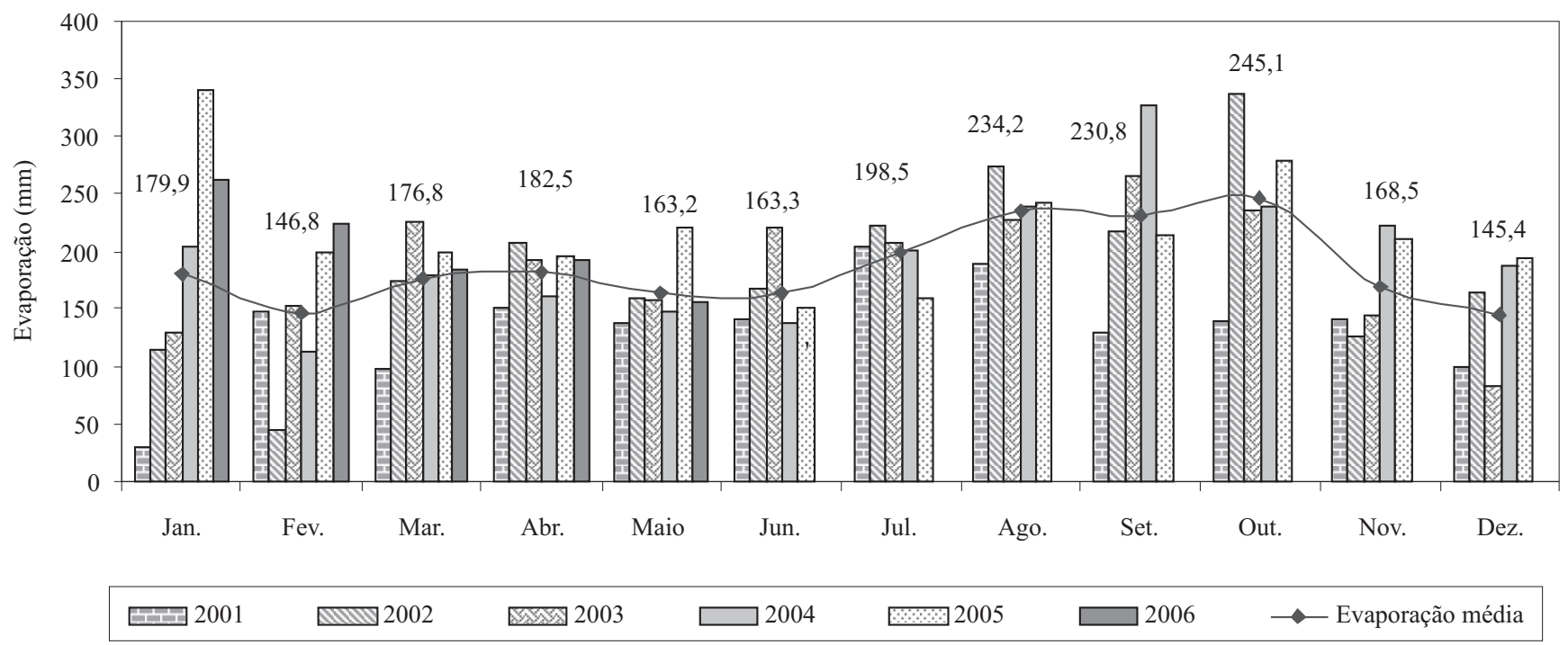

Figura 2. Evaporação de água em tanque Classe A, na Fazenda Experimental do Glória, Uberlândia, MG, de janeiro 2001 a maio de 2006 (valores acima das colunas referem-se às médias mensais). 
maturação e formação de botões pode não afetar a produtividade no ano, mas prejudica seriamente a produção no ano seguinte.

As análises individuais indicam que as lâminas de irrigação influenciaram significativamente a produtividade do cafeeiro, em 2003, 2004, 2005 e 2006.

Em 2005, a produção de grãos variou muito entre plantas e também entre as repetições dos tratamentos, o que resultou no aumento do coeficiente de variação. Pelo fato de as variâncias da produtividade terem sido heterogêneas, de acordo com o teste de Bartlett, foi feita a transformação dos dados obtidos no campo, para se realizar a análise de variância.

As plantas que receberam lâminas de 120 e $150 \%$ da ECA produziram, em média, 71,6 e 65,9 sacas ha $^{-1}$, respectivamente. Apesar de o índice pluviométrico ser considerado satisfatório - em média $1.712 \mathrm{~mm}$ anuais -, existiram vários meses em que foi observada baixa precipitação e altos índices de evaporação, o que resultou na redução da produtividade das plantas cultivadas em regime de sequeiro (média 22,3 sacas ha-1).

$\mathrm{Na}$ Figura 3, são apresentadas as equações de regressão dos dados originais de produtividade. Na primeira safra, a maior produtividade estimada foi de 67,4 sacas ha $^{-1}$, obtida com a lâmina de $137,5 \%$ da ECA. Na colheita seguinte, constatou-se o mesmo efeito quadrático da irrigação, e a estimativa da máxima produtividade foi de 115 sacas ha $^{-1}$, com a lâmina de $164,1 \%$ da ECA, produção $447 \%$ maior que na ausência de irrigação. Esse substancial aumento na produtividade dos cafeeiros irrigados difere dos resultados encontrados por Alves (1999) e Fernandes et al. (2000), que conduziram experimentos em Lavras e Planaltina de Goiás, respectivamente, e obtiveram, com as cultivares Acaiá MG-1474 e Mundo Novo, aumentos de 53,9\% e de $100 \%$, na produção das plantas irrigadas, em relação às que receberam água apenas das chuvas. Diferenças nas precipitações pluviais, ocorridas nos diversos locais e anos em que foram conduzidos os experimentos, podem explicar a divergência nos resultados.

Não é tão simples estabelecer comparações de produtividade entre ensaios, já que ela depende da bienalidade, cultivar, densidade de plantio e condições climáticas que variam de ano para ano. Em 2005, a produtividade teve comportamento completamente distinto de 2004, e variou exponencialmente em conseqüência dos níveis de água. Estimou-se, por meio da equação de regressão do ano 2005, uma colheita máxima de 36 sacas ha $^{-1}$, referente à lâmina de $13 \%$ da ECA. É provável que a queda de produção, observada na maioria dos tratamentos irrigados, ocorreu em razão da alta produtividade nesses tratamentos em 2004, que levaram ao esgotamento de reservas para a safra 2005.

Em 2006, a produção foi novamente elevada, como em 2004, e atingiu um valor máximo de 112,1 sacas ha ${ }^{-1}$, com a aplicação de 161,1\% da ECA. Esta melhor lâmina diverge da encontrada por Karasawa (2001), em Lavras (MG), que demonstrou que a reposição de $120 \%$ da ECA elevou a produção do cafeeiro 'Topázio MG-1190' em quase 15 vezes mais que a testemunha. É provável que esta diferença nas lâminas ótimas seja decorrente das diferenças climáticas entre as duas localidades.

A análise conjunta das quatro produções indica que a interação lâmina $\mathrm{x}$ ano foi significativa, a $1 \%$ de probabilidade, pelo teste $\mathrm{F}$. O coeficiente de variação de $17,04 \%$ revela boa precisão experimental. Como as lâminas foram analisadas em cada ano, por meio de regressões polinomiais, para comparação entre as safras realizou-se apenas o desdobramento de ano, dentro de cada lâmina, e a comparação das médias das quatro safras (Tabela 1). Nos tratamentos de 0 e $30 \%$ da ECA, a quarta safra superou as anteriores. Nos demais tratamentos, a produtividade de 2006 continuou sendo

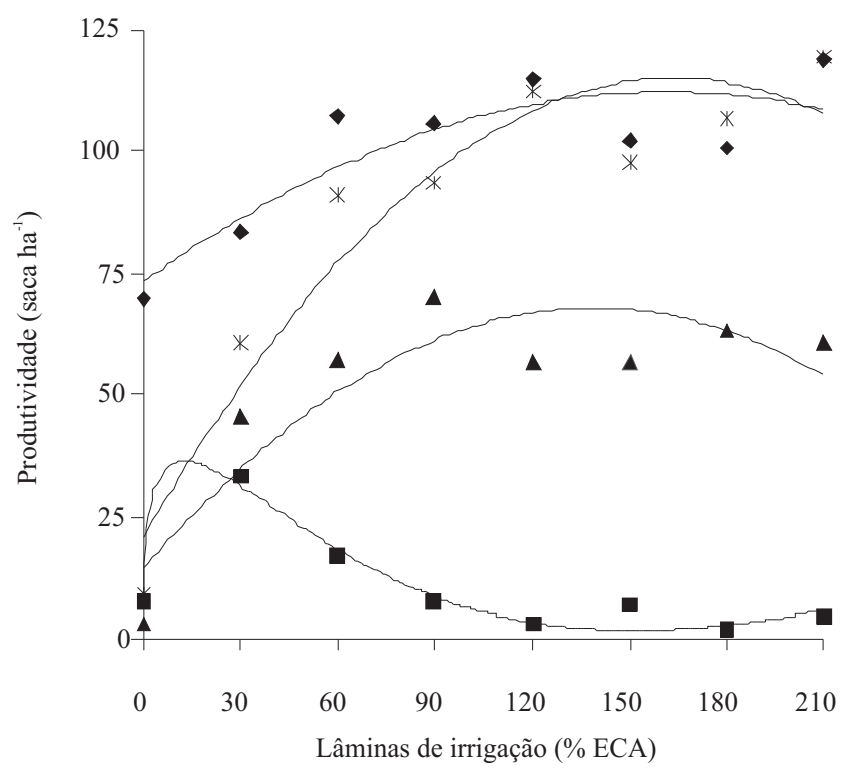

Figura 3. Representação gráfica da produtividade do cafeeiro (sacas ha' ${ }^{-1}$ ) nas quatro primeiras safras, em função de lâminas de irrigação calculadas com base na evaporação de água em tanque Classe A(ECA). ^ $2003 \mathrm{y}=-0,0028 \mathrm{x}^{2}+0,77 \mathrm{x}+14,424$, $\mathrm{R}^{2}=0,7908 ; * 2004 \mathrm{y}=-0,0035 \mathrm{x}^{2}+1,1485 \mathrm{x}+20,896, \mathrm{R}^{2}=0,8995$; $2005 \mathrm{y}=-219,669+17,709 \mathrm{x}^{0,45}+226,92 \mathrm{e}^{-0,00977 \mathrm{x}}, \mathrm{R}^{2}=0,9447$; $\checkmark 2006 \mathrm{y}=-0,0015 \mathrm{x}^{2}+0,4833 \mathrm{x}+73,213, \mathrm{R}^{2}=0,7376$. 
elevada, porém não diferiu da safra de 2004. Esse comportamento é indício de que o uso de irrigação não diminui a bienalidade do cafeeiro, já que em 2005 foram registradas menores produções, nos tratamentos em que as lâminas foram maiores que $60 \%$ da ECA. Esses resultados condizem com os de Faria \& Siqueira (2005), que constataram que a irrigação o ano todo, com umidade do solo superior a $30 \%$ da água disponível, não reduz a bienalidade de produção do cafeeiro.

A análise de variância revelou que apenas em 2005, ano de baixa produção, não houve diferença de rendimento em consequiência das lâminas de irrigação. Todavia, houve influência das lâminas em 2003, 2004 e 2006. Os dados deste experimento contradizem os de Vilela et al. (2002), que não encontraram diferença significativa no rendimento das duas primeiras safras do cafeeiro 'Rubi', cultivado em Lavras, com lâminas de irrigação de 0 a $140 \%$ da ECA.

Nas duas primeiras colheitas, o rendimento apresentou um comportamento quadrático, com curvas de resposta côncavas para cima (Figura 4). Entre os tratamentos avaliados, os de $120 \%$ e $150 \%$ da ECA propiciaram, em média, os melhores rendimentos, de 453,7 e 439,8 $\mathrm{L} \mathrm{saca}^{-1}$, respectivamente, enquanto na testemunha obteve-se o pior rendimento médio $\left(602,5 \mathrm{~L} \mathrm{saca}^{-1}\right)$. Constata-se, de acordo com a equação quadrática, referente ao ano de 2003, que a lâmina de melhor desempenho foi a de 143,7\% da ECA, com rendimento de 400,9 $\mathrm{L} \mathrm{saca}^{-1}$. Nessa ocasião, houve redução de $17 \%$ no volume de "café da roça", necessário para compor uma saca de café beneficiado, em relação ao tratamento não irrigado. Contudo, um ano depois, conforme a equação de 2004, seriam gastos por saca apenas $291,8 \mathrm{~L}$ de "café da roça", mediante a aplicação de $143 \%$ da ECA.

Tabela 1. Produtividade do cafeeiro (sacas ha-1), para cada nível de irrigação, ao longo dos anos ${ }^{(1)}$.

\begin{tabular}{ccrrrr}
\hline Lâminas & \multicolumn{4}{c}{ Anos } & Média \\
\cline { 2 - 5 }$(\% \text { ECA })^{(2)}$ & 2003 & 2004 & 2005 & 2006 & \\
\hline 0 & $3,23 \mathrm{~b}$ & $8,93 \mathrm{~b}$ & $7,36 \mathrm{~b}$ & $69,61 \mathrm{a}$ & 22,28 \\
30 & $45,58 \mathrm{bc}$ & $60,86 \mathrm{~b}$ & $33,45 \mathrm{c}$ & $83,58 \mathrm{a}$ & 55,87 \\
60 & $57,27 \mathrm{~b}$ & $91,12 \mathrm{a}$ & $17,08 \mathrm{c}$ & $107,21 \mathrm{a}$ & 68,17 \\
90 & $70,15 \mathrm{~b}$ & $93,81 \mathrm{a}$ & $7,44 \mathrm{c}$ & $105,84 \mathrm{a}$ & 69,31 \\
120 & $56,51 \mathrm{~b}$ & $112,13 \mathrm{a}$ & $2,88 \mathrm{c}$ & $114,98 \mathrm{a}$ & 71,62 \\
150 & $56,73 \mathrm{~b}$ & $97,78 \mathrm{a}$ & $7,23 \mathrm{c}$ & $102,05 \mathrm{a}$ & 65,95 \\
180 & $63,20 \mathrm{~b}$ & $106,53 \mathrm{a}$ & $2,28 \mathrm{c}$ & $100,55 \mathrm{a}$ & 68,14 \\
210 & $60,77 \mathrm{~b}$ & $119,58 \mathrm{a}$ & $4,64 \mathrm{c}$ & $119,13 \mathrm{a}$ & 76,03 \\
\hline Média & 51,68 & 86,34 & 10,29 & 100,37 & 62,17 \\
CV $(\%)$ & 14,45 & 12,48 & 61,45 & 12,82 & \\
\hline
\end{tabular}

(1) Médias seguidas por letras iguais, na linha, não diferem entre si pelo teste de Tukey, a 5\% de probabilidade; DMS $=19,60 .{ }^{(2)}$ Percentagem de reposição de água, de acordo com a evaporação em tanque Classe A.
Em 2006, a irrigação exerceu efeito linear decrescente sobre o rendimento. O tratamento de $0 \%$ da ECA apresentou, novamente, o pior rendimento, tendo sido necessários $514,7 \mathrm{~L} \mathrm{saca}^{-1}$. Para cada $1 \%$ da ECA reposta ao solo pelo gotejamento, a equação indicou melhoria no rendimento de $0,71 \mathrm{~L} \mathrm{saca}^{-1}$, observandose, no tratamento de $210 \%$ da ECA o rendimento de $365,7 \mathrm{~L} \mathrm{saca}^{-1}$.

Esses resultados estão coerentes com os encontrados por Karasawa (2001) e Vilella (2001), que trabalharam com as cultivares Topázio MG-1190 e Acaiá MG-1474, respectivamente, e obtiveram resposta positiva da irrigação sobre o rendimento. O primeiro conseguiu rendimento de 428,9 $\mathrm{L} \mathrm{saca}^{-1}$, com a reposição de $100 \%$ da ECA, enquanto o segundo obteve, com $120 \%$ da ECA, rendimento de $408 \mathrm{~L} \mathrm{saca}^{-1}$.

O efeito das lâminas aplicadas sobre o rendimento dependeu do ano $(\mathrm{CV}=25,02 \%)$, já que a análise de variância indicou interação significativa entre esses fatores.

Pelo desdobramento dos anos, para cada lâmina em estudo, sem o uso da irrigação, notam-se melhores rendimentos em 2003 e 2006, que não diferiram de 2005 (Tabela 2).

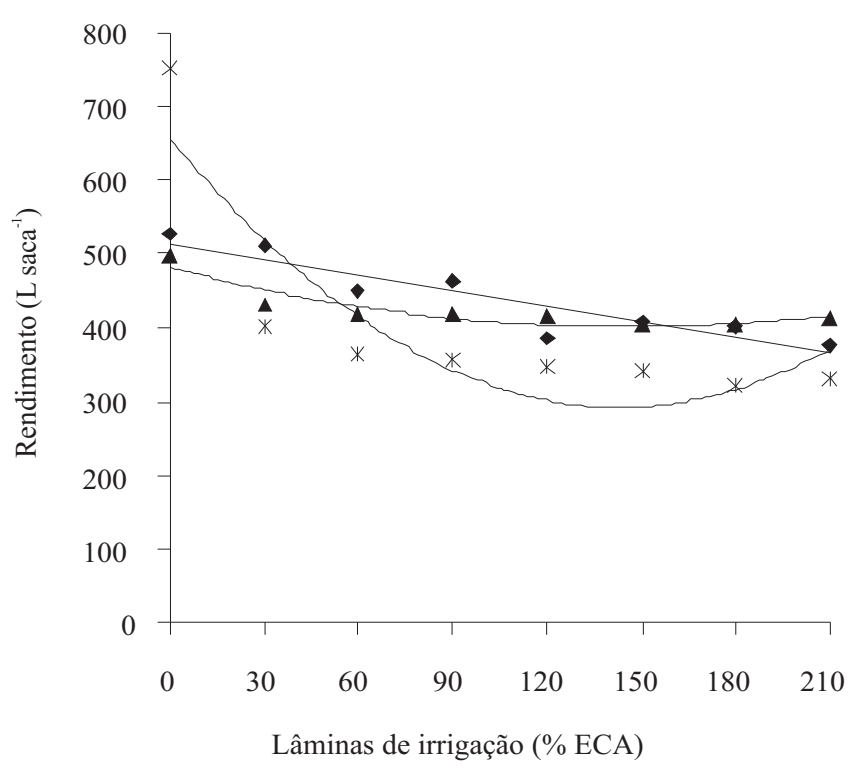

Figura 4. Representação gráfica do rendimento do cafeeiro $\left(\mathrm{L} \mathrm{saca}^{-1}\right)$ nas quatro primeiras safras, em função de lâminas de irrigação calculadas com base na evaporação de água em tanque Classe A (ECA). ^ $2003 \mathrm{y}=0,0039 \mathrm{x}^{2}-1,1206 \mathrm{x}+481,37$, $\mathrm{R}^{2}=0,8357 ; * 2004 \mathrm{y}=0,178 \mathrm{x}^{2}-5,0892 \mathrm{x}+655,56, \mathrm{R}^{2}=0,7784$; 2005 Não-significativo; $\$ 2006 y=-0,7095 x+514,7, R^{2}=0,8573$. 
Tabela 2. Rendimento do cafeeiro $\left(\mathrm{L} \mathrm{saca}^{-1}\right)$, para cada nível de irrigação, ao longo dos $\operatorname{anos}^{(1)}$.

\begin{tabular}{clclll}
\hline Lâminas & \multicolumn{4}{c}{ Anos } & Média \\
\cline { 2 - 5 }$(\% \text { ECA })^{(2)}$ & 2003 & 2004 & 2005 & 2006 & \\
\hline 0 & $498,81 \mathrm{a}$ & $751,67 \mathrm{~b}$ & $633,99 \mathrm{ab}$ & $525,50 \mathrm{a}$ & 602,49 \\
30 & $429,79 \mathrm{a}$ & $400,93 \mathrm{a}$ & $450,64 \mathrm{a}$ & $510,86 \mathrm{a}$ & 448,05 \\
60 & $416,59 \mathrm{ab}$ & $361,70 \mathrm{a}$ & $599,10 \mathrm{~b}$ & $450,50 \mathrm{ab}$ & 456,97 \\
90 & $416,88 \mathrm{a}$ & $357,31 \mathrm{a}$ & $703,52 \mathrm{~b}$ & $461,18 \mathrm{a}$ & 484,72 \\
120 & $414,53 \mathrm{a}$ & $346,20 \mathrm{a}$ & $667,46 \mathrm{~b}$ & $386,68 \mathrm{a}$ & 453,72 \\
150 & $403,47 \mathrm{ab}$ & $339,64 \mathrm{a}$ & $607,62 \mathrm{~b}$ & $408,64 \mathrm{ab}$ & 439,84 \\
180 & $405,75 \mathrm{a}$ & $321,23 \mathrm{a}$ & $708,41 \mathrm{~b}$ & $401,41 \mathrm{a}$ & 459,20 \\
210 & $410,59 \mathrm{a}$ & $332,53 \mathrm{a}$ & $777,49 \mathrm{~b}$ & $376,85 \mathrm{a}$ & 474,36 \\
\hline Média & 424,55 & 401,40 & 643,53 & 440,20 & 477,42 \\
CV $(\%)$ & 8,86 & 34,43 & 29,07 & 8,89 & \\
\hline
\end{tabular}

${ }^{(1)}$ Médias seguidas por letras iguais, na linha, não diferem entre si pelo teste de Tukey, a 5\% de probabilidade; DMS $=215,37$. (2)Percentagem de reposição de água, de acordo com a evaporação em tanque Classe A.

A aplicação de $30 \%$ da ECA não promoveu diferença no rendimento entre as quatro colheitas. Nos demais tratamentos irrigados, verificou-se que os rendimentos em 2003, 2004 e 2006 foram semelhantes. No entanto, o ano 2005 mostrou-se inferior, com péssimos rendimentos nas reposições de lâminas iguais ou superiores a $60 \%$ da ECA. É possível que este fato tenha ocorrido em razão da alta produtividade nesses tratamentos em 2004, que podem ter ocasionado redução das reservas de fotoassimilados e, por conseqüência, ter limitado o desenvolvimento dos grãos em 2005, o que interferiu negativamente também no rendimento.

\section{Conclusões}

1. Nas quatro primeiras safras, a produtividade do cafeeiro é influenciada pela irrigação e, em média, piores produtividades e rendimentos são observados nas plantas cultivadas em sequeiro.

2. A irrigação não ameniza a bienalidade de produção do cafeeiro, nas condições em que o experimento foi realizado.

\section{Referências}

ALVES, M.E.B. Respostas do cafeeiro (Coffea arabica L.) a diferentes lâminas de irrigação e fertirrigação. 1999. 94p. Dissertação (Mestrado) - Universidade Federal de Lavras, Lavras.

BANZATTO, D.A.; KRONKA, S.N. Experimentação agrícola. 4.ed. Jaboticabal: Funep, 2006. 237p.

CAMARGO, A.P de. Balanço hídrico, florescimento e necessidade de água para o cafeeiro. In: SIMPÓSIO SOBRE MANEJO DE ÁGUA
NAAGRICULTURA, 1987, Campinas. Anais. Campinas: Fundação Cargill, 1987. p.53-90.

CAMARGO, A.P. de. Florescimento e frutificação de café arábica nas diferentes regiões cafeeiras do Brasil. Pesquisa Agropecuária Brasileira, v.20, p.831-839, 1985.

FARIA, R.T. de; SIQUEIRA, R. Produtividade do cafeeiro e cultivos intercalares sob diferentes regimes hídricos. Bragantia, v.64, p.583590, 2005 .

FERNANDES, A.L.T.; SANTINATO, R.; LESSI, R.; YAMADA, A.; SILVA, V.A. Deficiência hídrica e uso de granulados em lavoura cafeeira irrigada por gotejamento. Revista Brasileira de Engenharia Agrícola e Ambiental, v.4, p.376-381, 2000.

GERVÁSIO, E.S. Efeito de diferentes lâminas de água no desenvolvimento do cafeeiro (Coffea arabica $\mathrm{L}$.) na fase inicial de formação da lavoura. 1998. 58p. Dissertação (Mestrado) Universidade Federal de Lavras, Lavras.

GOMES, N.M.; LIMA, L.A.; CUSTÓDIO, A. de P. Crescimento vegetativo e produtividade do cafeeiro irrigado no Sul do Estado de Minas Gerais. Revista Brasileira de Engenharia Agrícola e Ambiental, v.11, p.564-570, 2007.

GUIMARÃES, P.T.G.; GARCIA, A.W.R.; ALVAREZ VENEGAS, V.H.; PREZOTTI, L.C.; VIANA, A.S.; MIGUEL, A.E.; MALAVOLTA, E.; CORRÊA, J.B.; LOPES, A.S.; NOGUEIRA, F.D.; MONTEIRO, A.V.C. Cafeeiro. In: RIBEIRO, A.C.; GUimarÃES, P.T.G.; ALVAREZ VENEGAS, V.H. (Ed.). Recomendação para o uso de corretivos e fertilizantes em Minas Gerais: 5ª aproximação. Viçosa: CFSEMG, 1999. p.289-302.

KARASAWA, S. Crescimento e produtividade do cafeeiro (Coffea arabica L. cv. Topázio MG-1190) sob diferentes manejos de irrigação localizada. 2001. 72p. Dissertação (Mestrado) Universidade Federal de Lavras, Lavras.

KARASAWA, S.; FARIA, M.A. de; GUIMARÃES, R.J. Resposta do cafeeiro cv. Topázio MG-1190 submetido a diferentes épocas de irrigação. Revista Brasileira de Engenharia Agrícola e Ambiental, v.6, p.28-34, 2002.

MATIELLO, J.B. O café do cultivo ao consumo. São Paulo: Globo, 1991. 320p.

MOREIRA, C.F. Caracterização de sistemas de café orgânico sombreado e a pleno sol no Sul de Minas Gerais. 2003. 78p. Dissertação (Mestrado) - Escola Superior de Agricultura Luiz de Queiroz, Piracicaba.

OMETTO, J.C. Bioclimatologia vegetal. São Paulo: Ceres, 1981. $425 \mathrm{p}$.

ROTONDANO, A.K.F. Desenvolvimento vegetativo, produção e qualidade dos grãos do cafeeiro (Coffea arabica L.) sob diferentes lâminas de irrigação. 2004. 60p. Dissertação (Mestrado) - Universidade Federal de Uberlândia, Uberlândia.

SANTOS, M.L. Espaçamentos para cafeeiro (Coffea arabica L.) com e sem irrigação em região de cerrado. 2005. 44p. Dissertação (Mestrado) - Universidade Estadual Paulista, Ilha Solteira. 
SATURNINO, H.M. (Ed.). Balanço do CBP\&D: em 10 anos de investimentos em pesquisa, café brasileiro dobra produtividade e melhora a qualidade. Revista Item: Irrigação e Tecnologia Moderna, v.73, p.10-21, 2007.

SILVA, A.L. da; FARIA, M.A. de; REIS, R.P. Viabilidade técnicoeconômica do uso do sistema de irrigação por gotejamento na cultura do cafeeiro. Revista Brasileira de Engenharia Agrícola e Ambiental, v.7, p.37-44, 2003.

VILELA, L.A.A.; GOMES, N.M.; MARTINS, C.P. Avaliação da produtividade, rendimento, maturação e tamanho dos grãos das duas primeiras safras de café irrigado por pivô central, sob diferentes regimes de irrigação. In: CONGRESSO BRASILEIRO DE PESQUISAS CAFEEIRAS, 28., 2002, Caxambu, MG. Trabalhos apresentados. Rio de Janeiro: Mapa: Procafé, 2002. p.153-155.

VILELLA, W.M.C. Diferentes lâminas de irrigação e parcelamentos de adubação no crescimento, produtividade e qualidade dos grãos do cafeeiro (Coffea arabica L.). 2001. 96p. Dissertação (Mestrado) - Universidade Federal de Lavras, Lavras.

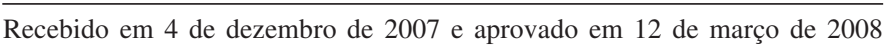

